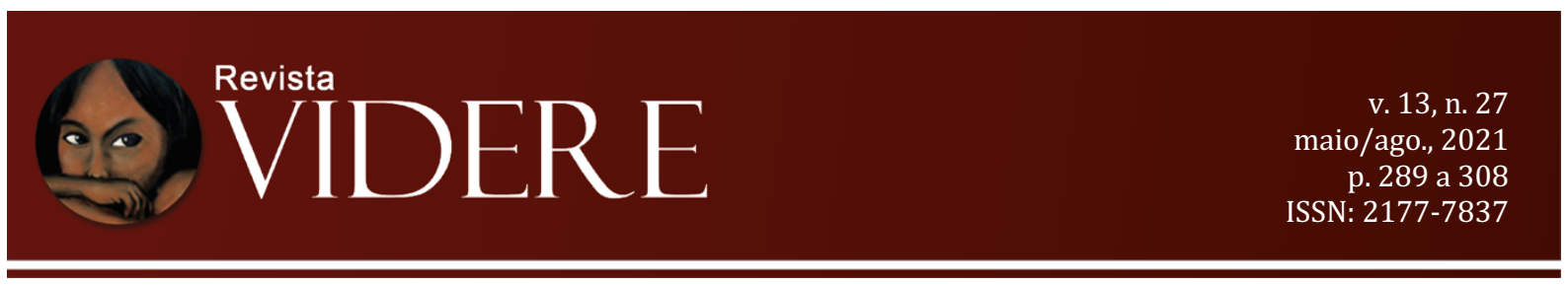

\title{
INTERCULTURALIDADE E CONSTITUCIONALISMO: UMA ANÁLISE DA EXPERIÊNCIA BOLIVIANA
}

\author{
INTERCULTURALITY AND CONSTITUTIONALISM: \\ ANALYSING BOLIVIAN EXPERIENCE \\ INTERCULTURALIDAD Y CONSTITUCIONALISMO: \\ UN ANALISIS DE LA EXPERIENCIA BOLIVIANA
}

\begin{abstract}
Milena Petters Melo
Doutora em Direito pela Università del Salento, Itália (2004). Professora Titular do Departamento de Direito e do Programa de Pos-Graduaçao em Direito da Universidade Regional de Blumenau, FURB. mpettersmelo@gmail.com OrcidID: https://orcid.org/0000-0001-5044-2382
\end{abstract}

Thiago Burckhart Doutorando em Diritto Comparato e Processi di Integrazione pela Università degli Studi della Campania Luigi Vanvitelli, Italia. thiago.burckhart@gmail.com OrcidID: https://orcid.org/0000-0001-5483-9336

Resumo: Tomando em consideração o reconhecimento constitucional da interculturalidade como princípio fundamental da Constituição boliviana de 2009 , este trabalho analisa a emergência do "constitucionalismo intercultural" na Bolívia, buscando compreender a atuação do Tribunal Constitucional Plurinacional na aplicação deste princípio. A hipótese é de que a aplicação judicial da interculturalidade, mediante um método intercultural, reforça a compreensão de que a interculturalidade se projeta como fundamento do constitucionalismo boliviano, como parte da identidade constitucional boliviana e também como elemento de continuidade do "processo constitucional emancipatório" e revolucionário, por meio do qual nasce a necessidade de cotejá-lo com os demais dispositivos constitucionais na atividade jurisdicional e política. A análise parte da teoria constitucional e dogmática constitucional boliviana em chave funcional-estrutural, conjugando elementos de teoria política e teoria da cultura, sendo realizado a partir de análise jurisprudencial, e divide-se em quatro partes: I - A politização da interculturalidade; II - A interculturalidade como princípio constitucional; III O princípio da interculturalidade e o Tribunal Constitucional Plurinacional; IV - Um "constitucionalismo intercultural". Como conclusão, tem-se a confirmação das hipóteses de pesquisa, além da constatação de que a Bolívia realiza uma experiência inovadora no âmbito 
do constitucionalismo democrático, que se projeta como um desafio para este país, sobretudo em razão da crise politica que marca a realidade boliviana ao menos desde 2018.

Palavras-chave: Interculturalidade. constitucionalismo. Bolívia. Tribunal Constitucional Plurinacional. constitucionalismo intercultural.

Abstract: Taking in consideration the constitutional recognition of interculturality as a fundamental principle of the Bolivian Constitution of 2009, this study analyzes the emergence of "intercultural constitutionalism" in Bolivia, seeking to clarify the role of the Plurinational Constitutional Court in applying this principle. The hypothesis is that the judicial application of interculturality, through an intercultural method, reinforces the understanding that interculturality is projected as the foundation of Bolivian constitutionalism, as part of the Bolivian constitutional identity and also as an element of continuity of the revolutionary and "emancipatory constitutional process", in which emerges the need to collate it with the other constitutional elements, and also with judicial and political practices. The analysis is grounded in constitutional theory and Bolivian constitutional law, in a functional-structural perspective, combining elements of political theory and cultural theory, being carried out based on jurisprudential analysis, and is divided into four parts: I - The politicization of interculturality; II - Interculturality as a constitutional principle; III - The principle of interculturality and the Plurinational Constitutional Court; IV - An "intercultural constitutionalism". As a conclusion, there is the confirmation of the research hypotheses, and also the verification that Bolivia realizes an innovative experiment in the field of democratic constitutionalism, that projects itself as a challenge for this country, especially because of the political crisis that has marked the Bolivian reality since at least 2018 .

Keywords: Interculturality. constitutionalism. Bolivia. Tribunal Constitucional Plurinacional. democratic constitutionalism.

Resumen: Tomando en consideración el reconocimiento constitucional de la interculturalidad como principio fundamental de la Constitución boliviana de 2009, este estudio analiza el surgimiento del "constitucionalismo intercultural" en Bolivia, buscando esclarecer el rol de la Corte Constitucional Plurinacional en la aplicación de este principio. La hipótesis es que la aplicación judicial de la interculturalidad, a través de un método intercultural, refuerza el entendimiento de que la interculturalidad se proyecta como fundamento del constitucionalismo boliviano, como parte de la identidad constitucional boliviana y también como elemento de continuidad del "proceso constitucional revolucionario" y emancipador, en el que surge la necesidad de cotejarlo con los demás elementos constitucionales, y también con las prácticas judiciales y políticas. El análisis se fundamenta en la teoría constitucional y el derecho constitucional boliviano, en una perspectiva funcional-estructural, combinando elementos de teoría política y teoría cultural, siendo realizado con base en el análisis jurisprudencial, y se divide en cuatro partes: I - La politización de la interculturalidad; II - La interculturalidad como principio constitucional; III - El principio de interculturalidad y el Tribunal Constitucional Plurinacional; IV - Un "constitucionalismo intercultural". Como conclusión, está la confirmación de las hipótesis de investigación, y también la constatación de que Bolivia realiza un experimento innovador en el campo del constitucionalismo democrático, que se proyecta como un desafío para este país, especialmente desde la crisis política que ha marcado la realidad boliviana desde al menos 2018. 
Palabras clave: Interculturalidad. constitucionalismo. Bolivia. Tribunal Constitucional Plurinacional. constitucionalismo democrático.

\section{Introdução}

O recente processo de "politização da cultura" no mundo ocidental resultou na sua projeção enquanto uma questão propriamente jurídico-constitucional. Desde a década de 1980, o redesenho político da América do Sul abriu caminho para a inserção das demandas culturais, do multiculturalismo e da interculturalidade, no interior dos textos constitucionais. $\mathrm{O}$ fortalecimento do movimento indígena desde a década de 1970 - e, sobretudo, no início do século XX - repaginou o indigenismo histórico no subcontinente e ampliou seu protagonismo nas Assembleias Nacionais Constituintes e em processos de reformas constitucionais, posicionando no âmbito do debate político-constitucional as reivindicações pelo reconhecimento de identidades historicamente marginalizadas da tutela constitucional e política.

A Constituição boliviana de 2009 se enquadra - juntamente com a Constituição equatoriana de 2008 - como expoente do "constitucionalismo andino". As reformas constitucionais realizadas por seu texto representam uma autêntica refundação do Estado boliviano com base na cosmovisão indígena - maior grupo étnico do país. No artigo $1^{\mathrm{o}}$ do seu texto, relativo ao "modelo de Estado", é previsto que a Bolívia constitui-se como um Estado de Direito Plurinacional e Intercultural, fundado na pluralidade e no pluralismo político, econômico, jurídico, cultural e linguístico, no interior do processo de integração. Trata-se, portanto, da configuração da interculturalidade como um genuíno princípio do Estado e da Constituição. $\mathrm{O}$ ambicioso projeto constitucional, entretanto, projeta questionamentos sobre sua aplicabilidade no campo da práxis política e judicial. Ele exige uma abertura significativa da hermenêutica constitucional na direção do pluralismo cultural e do diálogo intercultural. $\mathrm{O}$ Tribunal Constitucional Plurinacional, órgão máximo do Judiciário do país, é a instituição responsável por velar pela supremacia constitucional e pela interpretação constitucional, de modo que possui um papel central no âmbito do constitucionalismo intercultural e do desenho do diálogo intercultural determinado pelo texto constitucional.

Tomando isto em consideração, este trabalho tem por objetivo analisar a emergência do "constitucionalismo intercultural" na Bolívia, buscando compreender a atuação do Tribunal Constitucional Plurinacional na aplicação do "princípio da interculturalidade". Para tanto, analisa-se uma decisão paradigmática da Corte, proferida no ano de 2014 (Declaración 
Constitucional Plurinacional 030/2014) e de seus fundamentos teóricos e jurídicos. A hipótese é de que a aplicação judicial deste princípio, por meio de uma interpretação constitucional plural dos direitos fundamentais, reforça a compreensão de que a interculturalidade se projeta como fundamento do constitucionalismo boliviano, como parte da identidade constitucional boliviana e também como elemento de continuidade do "processo constitucional emancipatório" e revolucionário, por meio do qual nasce a necessidade de cotejá-lo com os demais dispositivos constitucionais na atividade jurisdicional e política. A análise parte da teoria constitucional e dogmática constitucional boliviana em chave funcional-estrutural, conjugando elementos de teoria política e teoria da cultura, sendo realizado a partir de análise jurisprudencial, e dividese em quatro partes: I - A politização da interculturalidade; II - A interculturalidade como princípio constitucional; III - O princípio da interculturalidade e o Tribunal Constitucional Plurinacional; IV - Um “constitucionalismo intercultural”.

\section{A politização da interculturalidade}

Desde os anos 1970, pode-se afirmar que houve uma mudança significativa no âmbito das reivindicações políticas. Autores como Alain Touraine (2007) descrevem que, desde então, desenhou-se um novo paradigma da vida em sociedade, caracterizado pela emergência das pautas "culturais". Este novo paradigma - um "paradigma cultural" - se caracteriza pelo nascimento e fortalecimento de movimentos "culturais" em grande parte do mundo ocidental e por sua projeção na arena pública, no espaço público democrático. Trata-se do movimento feminista, do movimento negro, do movimento dos refugiados, do movimento indígena, do movimento queer e daqueles vinculados a grupos étnicos minoritários em várias partes do mundo. Impulsionados pela intensificação da globalização - que não se limita a sua dimensão econômica do capitalismo neoliberal - e pelo aprofundamento das relações entre nações e povos, mostra-se evidente que houve efetivamente uma significativa mudança de eixo na esfera pública, dando sustentação para o desenvolvimento de novos conflitos político e sociais no globo (cfe. HALL, 2010; SANTOS, 1997).

Seyla Benhabib (2006) descreve esse fenômeno como a "politização da cultura", que compreende a politização da diferença cultural e o fortalecimento da "política identitária" no âmbito do universalismo liberal. Trata-se da constatação de que no interior das sociedades singulares existe uma imensidade de etnias, culturas, cosmovisões e, em alguns casos, nações, que, entretanto, foram marginalizadas desde a gênese do projeto moderno sob o signo do Estado-Nação, sendo relegadas ao apagamento cultural e à ausência de proteção jurídica e 
política para a manifestação de suas singularidades. A emergência dessas novas pautas impõe a tarefa de repensar e redesenhar o modelo de cidadania construído na modernidade ocidental e redimensionar o conceito de "justiça social” na esfera política e jurídica. Da mesma forma, implica em reconceber o modelo de democracia ${ }^{1}$ para que possa abrir espaço à participação desses grupos na esfera pública institucional, sem, entretanto, abdicar da herança do universalismo constitucional e jurídico no sistema de governo ${ }^{2}$, que se desenvolve por meio de “iterações democráticas” (BENHABIB, 2006). Em efeito, a politização da cultura abriu o caminho para se pensar e aplicar novas metodologias para lidar com o "problema" do pluralismo cultural no interior das sociedades complexas.

Historicamente, pode-se apontar para pelo menos dois "modelos" de gestão do pluralismo e da diferença ${ }^{3}$, que tiveram proeminência na Bolívia e, de modo geral, na América Latina: o assimilacionismo e a integraciosnimo ${ }^{4}$. O assimilacionismo se refere a uma prática política na qual ocorre a "total incorporação de um indivíduo ou grupo na sociedade nacional, com a perda de sua identidade étnica e cultural". Já o integracionismo "consistiria na participação na sociedade nacional sem a perda da identidade étnica" e cultural" (VILLASBOAS FILHO, 2003, p. 284). De acordo com Raquel Fajardo (2006), o integracionismo foi um dos marcos do constitucionalismo social na América Latina, ao passo que o assimilacionismo foi do constitucionalismo liberal. Apesar da diferença semântica entre os termos, ambos podem ser interpretados como sinônimos de uma prática que visa, em síntese, negar o "direito ao futuro" dos povos marginalizados do processo "civilizatório" a partir do apagamento de suas culturas, mediante a criação da "necessidade" de sua assimilação ou integração. Do ponto de vista jurídico, tratam-se de dois modelos que foram incorporados aos regimes de juridificação na Bolívia e na América Latina (cfe. VILLAS-BOAS FILHO, 2017).

O repaginamento do indigenismo histórico por meio do fortalecimento dos movimentos indígenas na região a partir da década de 1970 (cfe. RAMOS, 1997) foi o elemento propulsor para a revisão destes modelos de gestão do pluralismo cultural. A articulação indígena na América do $\mathrm{Sul}^{5}$ introduzira no debate político-constitucional - tanto nas

\footnotetext{
${ }^{1}$ Para aprofundamentos, ver: Held (1991).

2 Benhabib, assim como Habermas, aponta para o conceito de democracia deliberativa, cfe. Benhabib (2006); Habermas (1997).

${ }^{3}$ Para uma analise sobre a relação entre democracia, pluralismo e a "gesto da diversidade", ver Farinas Dulce (2014).

4 Também poderia se fazer referência ao "segregacionismo" como uma "metodologia política" que, em determinados momentos históricos, também fora utilizado para gerir o problema da diferença. No entanto, o assimilacionismo e o integracionismo são consensualmente trabalhados pela literatura jurídica e política como "modelos" dominantes.

${ }^{5}$ Para aprofundamentos sobre os momentos do indigenismo na América do Sul, ver: Ramos (2012).
} 
Assembleias Constituintes e reformas constitucionais subsequentes, quanto no campo das políticas públicas - o debate sobre o multiculturalismo e a interculturalidade. De acordo com Catherine Walsh (2008), o termo "interculturalidade" passou a fazer parte do léxico latinoamericano nos anos 1980, pensada num primeiro momento a partir das políticas educacionais no México. O debate, naquele tempo, circundava a proposta de uma "educação intercultural bilíngue”. Nos anos 1990, como explica Walsh (2008), o discurso sobre a interculturalidade passou a ser apropriado pelos povos indígenas do Equador que o associaram com o as questões jurídicas, linguísticas e de saúde pública ${ }^{6}$. Desde então, a interculturalidade passou a ser fortalecida como ideário para a gestão política e jurídica do pluralismo cultural também na Bolívia.

Como aponta Walsh, entretanto, "desde sus comienzos, la interculturalidad ha significado una lucha en la que han estado en permanente disputa asuntos como identificación cultural, derecho y diferencia, autonomía y nación" (WALSH, 2010, p. 79). Diferentemente do assimilacionismo e do integracionismo, a proposta da interculturalidade baseia-se na metodologia do "diálogo intercultural". Na perspectiva de Boaventura de Sousa Santos (1997), o diálogo intercultural se desenvolve por meio da "hermenêutica diatópica", ou seja, na tentativa de compreensão mútua da perspectiva e epistemologia dos diferentes sujeitos que interagem, no qual o sujeito permanece com um pé em sua cultura e o outro na cultura do outro sujeito. Como aponta Catherine Walsh (2008), a interculturalidade, entendida enquanto método, permite que o entendimento cultural entre duas culturas ou epistemologias - que, em determinados casos podem parecer inconciliáveis - torne-se possível, abrindo o caminho para o mútuo entendimento entre atores culturais diferenciados.

Cabe destacar, todavia, que a noção de interculturalidade se dessemelha do "multiculturalismo". Em efeito, pode-se dizer que o processo de "politização da cultura" estabeleceu esses dois novos métodos na gestão da pluralidade - o multiculturalismo e a interculturalidade -, mas ambos possuem abordagens e métodos diferentes para atuar neste campo. Enquanto a interculturalidade se propõe a efetivamente conviver, interagir e aprender com o outro, com a cultura "diferente" - tendo-se em vista o processo de hibridização das culturas (cfe. BHABHA, 2013) -, o multiculturalismo se propõe a "coexistir" (LOPES, 2012, p. 71) com o outro no mesmo espaço geográfico. A palavra-chave do multiculturalismo, portanto, é a "tolerância", compreendida como o caminho para a construção de uma sociedade

\footnotetext{
${ }^{6}$ Para aprofundamentos, também ver: Flores (2015).
} 
pacífica, ao passo que o "diálogo" está na centralidade da proposta da interculturalidade? Embora seja possível categorizar diversos modelos de "espaço multicultural", que se desenvolveram em diferentes contextos desde seu nascimento no debate público canadense e estadunidense na década de 1980 - como o modelo político liberal-clássico, o modelo liberal multicultural, o modelo multicultural "maximalista" e o modelo do multiculturalismo combinados, para ficar somente na classificação elaborada por Andrea Semprini (1999, p. 134143) -, o ideário da tolerância permanece nestes modelos na centralidade desta proposta de gestão política do pluralismo. A interculturalidade, entretanto, põe na centralidade de sua proposta a necessidade de superar a lógica da tolerância, visto que ela não contribui para a coesão social e para o entendimento mútuo entre sujeitos culturalmente "diferentes", mas, em determinados casos, pode ainda aprofundar desigualdades e animosidades no interior de uma sociedade.

No século XXI, a proposta da interculturalidade passa a se projetar politicamente como um "proyecto ético-político de acción transformativa y democracia radical", como aponta o jurista peruano Fidel Tubino (2005). Trata-se da necessidade de pensá-la criticamente enquanto metodologia política - ideal procedimental - e como paradigma democrático - ideal substancial. Ao insuflar sua dimensão substancial, abre-se o caminho para conciliar o pluralismo cultural com o projeto da modernidade e como uma possibilidade de convivência harmônica e impura entre diferentes culturas. Os povos indígenas da América do Sul e, em específico, os bolivianos, passaram a compreender a interculturalidade como uma proposta viável e, ao mesmo tempo, desafiadora para superar o passado de apagamento cultural - pois, muito embora os povos indígenas sejam etnicamente a maior parte da população boliviana, eles conviveram com um passado de apagamento político e jurídico. Como aponta Fidel Tubino (2005), a interculturalidade entendida enquanto um projeto normativo, propõe uma relação entre culturas diversas que se estabelecem vínculos em comum, na medida em que o Estado e a sociedade civil tornam-se responsáveis pela promoção gradual de espaços de interação positiva que permitam o diálogo intercultural, o reconhecimento mútuo, a convivência, o intercâmbio cultural, a cooperação e a convivência pacífica. Trata-se, pois, de um dos grandes desafios do direito e da política do século XXI.

\section{A interculturalidade como principio constitucional}

\footnotetext{
7 “Mientras que en el multiculturalismo la palabra clave es tolerancia, en la interculturalidad "la palabra clave es diálogo. La interculturalidad reasume en parte el multiculturalismo, en el sentido de que para dialogar hay que presuponer respeto mutuo y condiciones de igualdad entre los que dialogan", (TUBINO, 2002, p. 74).
} 
O constitucionalismo na América Latina pode ser categorizado em três grandes momentos histórico-políticos (cfe. GARGARELLA, 2013). O primeiro deles refere-se ao pacto realizado entre liberais e conservadores na gênese do constitucionalismo liberal do século XIX. O segundo diz respeito ao reconhecimento e inclusão nos textos constitucionais de direitos sociais no início do século XX, o que corresponde à formação do constitucionalismo social e do Estado social na região. Por fim, o terceiro momento trata de uma "onda" final de reformas e novas Constituições introduzidas a partir da década de 1980 do século XX e início do século XXI, marcadas pela ampliação do catálogo de direitos fundamentais, a constitucionalização da democracia e a abertura para a proteção jurídico-constitucional aos direitos humanos internacionalmente reconhecidos (GARGARELLA, 2013, p. 34-53) - no âmbito de um direito constitucional multinível (cfe. PIOVESAN, 2005). Esse processo se projeta em consonância com o desenvolvimento do constitucionalismo moderno na Europa, conforme a clássica análise teórica e histórica realizada por Norberto Bobbio (2004).

A referida "onda" final de reformas, que se estabeleceu nos últimos 40 anos, marcada por reformas constitucional em matéria indígena e multicultural é também dividida em três momentos conforme aponta Raquel Fajardo (2009). O primeiro ciclo de reformas constitucionais multiculturais "caracteriza-se pela introdução do direito - individual e coletivo - à identidade cultural, junto com a inclusão de direitos indígenas específicos" (FAJARDO, 2009, p. 25). Neste âmbito encontram-se as Constituições do Canadá (1982), Guatemala (1985) e Nicarágua (1987). O segundo ciclo, durante os anos 90 do século XX “incorpora os direitos contidos no Convênio 169 da OIT” (Organização Internacional do Trabalho) (FAJARDO, 2009 , p. 26). De acordo com Fajardo, este ciclo "afirma o direito (individual e coletivo) à identidade e diversidade cultural, já introduzido no primeiro ciclo, mas desenvolve com maior afinco o conceito de "nação multiétnica" e "estado pluricultural", qualificando a natureza da população e avançando rumo ao caráter do Estado" (FAJARDO, 2009, p. 26). Nele também se reconhecem novos direitos indígenas e direitos de populações afrodescentes. Neste ciclo, encontram-se as constituições do Brasil (1988), Colômbia (1991), México (1992), Paraguai (1992), Peru (1993), Bolívia (1994), Argentina (1994), Equador (1996) e Venezuela (1999). Por fim, o último ciclo das reformas constitucionais multiculturais, durante a primeira década do século XXI, “colocou no cenário um debate ainda não resolvido por dois processos constituintes [...] sobre o 'Estado Plurinacional' e um modelo de pluralismo legal igualitário, baseado no diálogo intercultural" (FAJARDO, 2009, p. 27). Neste último ciclo, encontram-se as Constituições do Equador (2008) e Bolívia (2009). 
A Constituição boliviana, juntamente com a equatoriana, são pioneiras no processo regional de constitucionalização da interculturalidade como princípio fundamental e "base fundamental del Estado" (MACHICADO, 2009, p. 38). Trata-se de uma inovação para o constitucionalismo latino-americano, na medida em que representa a abertura cognitiva do constitucionalismo para o reconhecimento da diversidade e não seu apagamento. Ainda, este reconhecimento não é feito de forma marginal no texto constitucional, mas ao princípio da interculturalidade é conferido lugar de destaque. A Constituição faz referência a ele logo em seu artigo 1, no qual dispõe que a Bolívia se constitui enquanto um Estado Intercultural, que se funda na pluralidade e no pluralismo cultural e linguístico, dentro do processo integrador do país $^{8}$. Em seu preâmbulo, faz-se referência à composição plural do povo boliviano e ao respeito à pluralidade social e cultural dos habitantes da terra. Ao longo de seu texto a palavra "cultura" aparece por 109 vezes, enquanto que a palavra "intercultural" aparece por 25 vezes.

O texto constitucional aponta que a constituição social do país é plural e se pauta na interculturalidade - em comunidades interculturais (artigo 3). Dispõe que é um fím e uma função essencial do Estado o fomento ao respeito mútuo e ao diálogo intercultural, intracultural e plurilíngue no país (artigo 9,1). Alia a proposta da interculturalidade com o pacifismo e com a criação de uma “cultura da paz", que compõe o respeito ao direito à paz e a cooperação entre os povos da região e do mundo (artigo 10,1). Garante o direito de todas as pessoas de receber educação em todos os níveis de maneira intercultural (artigo 17). Também garante o direito à saúde que deve ser desenvolvido mediante políticas públicas interculturais e intraculturais (artigo 18, III). Dispõe em capítulo específico sobre os direitos das nações, dos povos indígenas originários campesinos no qual prevê que no marco da unidade do Estado, estes povos gozam do direito à sua identidade, crença religiosa, práticas, costumes e própria cosmovisão (artigo 30 , II, 2); ao respeito aos seus saberes e conhecimentos tradicionais, sua medicina tradicional, seus idiomas, seus rituais, símbolos e vestimentas (artigo 30, II, 9)

A Constituição ainda dispõe que a seguridade social deve pautar-se na interculturalidade (artigo 45, II); que as mulheres tem direito à maternidade segura, baseada em uma visão e prática intercultural (artigo 45, V). O capítulo sexto das "Bases fundamentales del Estado" é dedicado à "Educación, Interculturalidad y Derechos Culturales", no qual se dispõe que a educação deve fomentar o civismo e o diálogo intercultural (artigo 79). Ademais, também

\footnotetext{
${ }^{8}$ Constituiçao da Bolivia: “Artículo 1. Bolivia se constituye en un Estado Unitario Social de Derecho Plurinacional Comunitario, libre, independiente, soberano, democrático, intercultural, descentralizado y con autonomías. Bolivia se funda en la pluralidad y el pluralismo político, económico, jurídico, cultural y lingüístico, dentro del proceso integrador del país".
} 
prevê, no campo do ensino superior, que as Universidades públicas devem estabelecer programas de desconcentração acadêmica e de interculturalidade, de acordo com as necessidades do Estado e das nações e povos indígenas originários campesinos (artigo 93, IV); e também devem as universidades criar e sustentar centros interculturais de formação e capacitação técnica e cultural, de acesso livre ao povo, em consonância com os princípios e fins do sistema educativo (artigo 95, I). A formação docente em todos os níveis também deve ser feita de forma intercultural (artigo 96, I). No capítulo específico que trata sobre "Culturas", dispõe em seu artigo 98 que:

$[\ldots]$

Artículo 98. I. La diversidad cultural constituye la base esencial del Estado Plurinacional Comunitario. La interculturalidad es el instrumento para la cohesión y la convivencia armónica y equilibrada entre todos los pueblos y naciones. La interculturalidad tendrá lugar con respeto a las diferencias y en igualdad de condiciones. ${ }^{9}$

No mesmo título, ainda faz-se referência que o Estado boliviano deve assumir como fortaleza a existência de culturas indígenas originário campesinas, depositárias de saber, conhecimentos, valores, espiritualidades e cosmovisões, sendo responsabilidade do Estado preservar, proteger e difundir as culturas existentes no país (artigo 98, II e III). No Título que trata das disposições do Tribunal Constitucional Plurinacional, a Constituição estabelece que o poder de dizer a justiça emana do povo boliviano e se sustenta, entre outros, no princípio da interculturalidade (artigo 178). A mesma disposição é reafirmada quando trata do Tribunal Agroambiental (artigo 186) e da "Defensoria del Pueblo" (artigo 218, II).

Os dispositivos acima identificados demonstram que houvera um amplo processo de constitucionalização da interculturalidade na Bolívia. A interculturalidade deixa de ser uma reivindicação da esfera pública de grupos subalternos para alçar-se a "princípio constitucional", que se encontra na base da Constituição de 2009. A constitucionalização desta demanda - que dialoga diretamente com a ideia de "plurinacionalidade", que também foi constitucionalizada - implica no redesenho do modelo de Estado, como é tratado pelo próprio texto constitucional. Em razão disso, o texto constitucional também prevê a ampliação da representatividade dessas populações nos ambientes institucionais, como é o caso dos tribunais, do parlamento e demais órgãos da administração pública ${ }^{10}$. Esta medida está em consonância com a obrigação

\footnotetext{
9 "Artigo 98. I. La diversidad cultural constituye la base esencial del Estado Plurinacional Comunitario. La interculturalidad es el instrumento para la cohesión y la convivencia armónica y equilibrada entre todos los pueblos y naciones. La interculturalidad tendrá lugar con respeto a las diferencias y en igualdad de condiciones.

${ }^{10}$ Para aprofundamentos, ver: Burckhart (2019, pp. 239-264).
} 
constitucional do Estado proporcionar o diálogo intercultural entre as diferentes culturas e epistemologia no interior do próprio Estado. Boaventura de Sousa Santos (2010) aponta que esse processo pode ser descrito como a "refundação do Estado" boliviano. Em efeito, Bartolomé Clavero (2011) aponta que o constitucionalismo na Bolívia tivera transformações pouco significantes desde seu início, tendo a Constituição de 2009 incorrido em uma ruptura com essa realidade história. A refundação do Estado por meio das epistemologias do sul, como descreve Boaventura, resulta em uma contribuição para o patrimônio comum do constitucionalismo democrático ${ }^{11}$.

Cabe ainda ressaltar que as conquistas do processo constitucional na Bolívia, que incluem o reconhecimento da interculturalidade como princípio constitucional, contribuíram para a expansão do campo político institucional por meio da inclusão de "atores que não participavam da política em espaços fora deste campo" (PANNAIN, 2018, p. 311) ${ }^{12}$. Trata-se de um processo político de mobilização que se intensificou no início do milênio com o aprimoramento do protagonismo indígena. A interculturalidade, nesse contexto, se projeta como um elemento central e fundamental para o processo de democratização das instâncias políticas e representativas da Bolívia, assim como para as Judiciais. Ela pode ser entendida como o elo que interliga o constitucionalismo e a democracia bolivianos, no âmbito das suas potencialidades e contradições, ações e tensões, que redesenham o sentido da política democrática e do pertencimento comunitário e político no país.

\section{O principio da interculturalidade e o Tribunal Constitucional Plurinacional}

O princípio constitucional da interculturalidade encontra-se na centralidade do “constitucionalismo transformador" na Bolívia (SANTOS \& RODRIGUEZ, 2012). Tendo isso em vista, o Tribunal Constitucional Plurinacional tem tido importante papel no sentido de afirmar este princípio como um efetivo “princípio constitucional”, além de desenvolver um método próprio de interpretação, chamado de "interpretação constitucional plural" dos direitos fundamentais, reforçando não somente a compreensão de que a interculturalidade é um elemento "constitutivo" do direito constitucional boliviano, mas também apontando que ele projeta-se como um elemento de "continuidade" do "processo constitucional emancipatório" e

\footnotetext{
${ }^{11}$ Para aprofundamentos, ver: Santos \& Meneses (2009).

${ }^{12}$ A autora ainda aponta que "É incontestável que a expansão do campo político institucional tenha incluído atores que antes participavam da política em espaços fora desse campo. A presença de vários homens e mulheres indígenas na Assembleia Legislativa Plurinacional é uma prova" (PANNAIN, 2018, p. 311).
} 
revolucionário, por meio do qual nasce a necessidade de cotejá-lo com os demais dispositivos constitucionais e infraconstitucionais na atividade jurisdicional e política.

Neste sentido, a Declaração Constitucional Plurinacional 030/2014 (TCP, 2014) ${ }^{13}$ projeta-se como exemplo paradigmático para a consolidação da força normativa do princípio constitucional da interculturalidade, bem como da construção de um método judicial de “interpretação constitucional"14. Trata-se de uma consulta apresentada pela Nação Uru Chipaya sobre a legitimidade jurídica de aplicação de sua cosmovisão e de seus costumes na mudança e destituição de autoridades e representantes políticos municipais. O pedido de consulta referiuse a um caso concreto ocorrido, no qual o representante indicado de acordo com os costumes da referida Nação não cumpriu com seus deveres no que se refere à representação a ele reconhecida. Na parte introdutória da decisão, na qual apresentam-se as características sociais, politicas e culturais da referida Comunidade, reconhece-se o seu modelo de "administração da justiça", caracterizado em três níveis escalonados: nível comunitário, nível Ayllu e, por fim, nível da Nação Uru, maior instância. Da mesma forma, também reconhece seus "Direitos e deveres" no marco de sua própria jurisdição, a eleição de suas autoridades e representantes por "usos e costumes" no qual aplicam procedimentos próprios.

Nesse sentido, no ano de 2010, ao aplicar o referido procedimento, a Nação elegeu como representante para Prefeito do município de Chipaya, um dos membros da referida Nação, Elias Felipe Villca. No entanto, ao ser empossado na função, passou a descumprir as recomendações, sugestões e resoluções das autoridades originárias reconhecidas pela Nação como legítimas. Dessa forma, a Assembleia Geral da Nação Uru Chipaya resolveu pela destituição do referido Prefeito, com fulcro em seus próprios "usos e costumes", e determinou a nomeação de um novo representante. A Nação elabora e aplica seu próprio sistema jurídico há centenas de anos e, dentre elas, encontra-se a norma que atribui o direito de destituição de representantes que incorram em contradição com as solicitações da comunidade. Nesse sentido, a Nação realizou a consulta diretamente no Tribunal Constitucional Plurinacional para o reconhecimento de suas práticas e procedimentos internos no caso em questão. A Corte Constitucional declarou, a partir da analise do caso, a "aplicabilidad de la decisión comunal de cambio y destitución de Elias Felipe Villca, al cargo de Alcalde Municipal de la Nación Uru

\footnotetext{
${ }^{13}$ Utiliza-se aqui a sigla TCP para designar Tribunal Constitucional Plurinacional.

${ }^{14}$ De acordo com o Codigo Procesual Constitucional da Bolivia (Ley de 5 de julio de 2012), uma Declaracion Constitucional Plurinacional é uma resolução adotada pelo Tribunal Constitucional Intercultural "en caso de control previo o consultas realizadas al Tribunal Constitucional Plurinacional" (art. 10, 2). De acordo com o art. 15 , I, seus efeitos são de cumprimento obrigatório e vinculante para as partes em um processo constitucional, elas constituem “jurisprudência” do Tribunal e são, portanto, aplicáveis em toda a Administração Pública do país.
} 
Chipaya, conforme sus principios y valores, normas y procedimientos propios en el marco de su jurisdicción” (TCP, 2014, p. 02).

Os fundamentos jurídicos da decisão são de interessante relevância. A decisão aponta para o processo de "descolonização" realizado pelas Constituições do Equador (2008) e da Bolívia (2009) no continente americano, fazendo insurgir um constitucionalismo "próprio" da América Latina, com características particulares e diferentes do constitucionalismo de matriz europeia $^{15}$. A decisão aponta que a Constituição da Bolívia contém quatro características essenciais desta nova "diferenciação": a) é fruto da luta anticolonial; b) a plurinacionalidade é considerada a forma própria de estatalidade, em que as diversidades (diferentes nações e comunidades) reconhecem o Estado, e não o inverso; c) assenta-se na descolonização jurídica; e, d) é orientada pelo "buen-vivir" (Suma Qamana), como um horizonte alternativo de modo de vida e de desenvolvimento que se contrapõe ao capitalismo, ao neoliberalismo e às formas de mercantilização e "coisificação" da vida (TCP, 2014, p. 11-12).

A decisão ainda aponta para mecanismos de interpretação plural do texto constitucional. Tomando em consideração as características essenciais do constitucionalismo boliviano, atrelado aos princípios éticos estabelecidos pelo texto constitucional - sobretudo no seu artigo 8.I -, assim como o próprio princípio constitucional da interculturalidade, a Corte aponta que a interpretação do texto constitucional deve ser realizada mediante método de “interpretação plural” ou "intercultural” para que seja efetivamente garantida. Trata-se de uma "herramienta hermenéutica de carácter plural y descolonizador" que vai ao encontro da necessidade de se estabelecer novos instrumentos e mecanismos hermenêuticos que caminhem em concomitância com as transformações ocorridas no seu texto (TCP, 2014, p. 14). Apontando para o Informe Técnico n. 55/2013, da Unidade de Descolonização do Tribunal Constitucional Plurinacional, a interpretação plural "es una herramienta hermenéutica de carácter multidimensional que implica la apertura a nuevas formas de observación que nacen fuera de los marcos de la 'razón jurídica' colonial” (TCP, 2014, p. 13).

De acordo, ainda, com o referido Informe Técnico, a hermenêutica plural é multidimensional na medida em que "no interpreta palabras o conceptos, sino las vivencias y experiencias que nacen desde lo geográfico, étnico-cultural y político", de modo que a "fuente de interpretación" é a "vivencia", “experiência", o "multidimensional” (TCP, 2014, p. 14-15). Desse modo, a decisão da Corte aponta que esta forma interpretativa objetiva dotar de conteúdo próprio as categorias e conceitos constitucionais desde a vivência e a experiência plural, 
fazendo-a dialogar com outros saberes e conhecimentos, na forma de uma "interpretación intercultural" (TCP, 2014, p. 15). A sentença estabelece que a "interpretação plural” se aplica em cada caso concreto do controle de constitucionalidade a partir dos seguintes critérios:

1) La cosmovisión y concepción filosófica, conexo a las identidades plurinacionales; que implica un proceso hermenéutico que parte desde los modos de concebir de las naciones y pueblos indígena originaria campesinas, tomando seriamente en cuenta el "sentido" filosófico propio de las categorías que emulan las autoridades que consultan.

2) Concomitancia con saberes históricos, lingüísticos, culturales, sociales, económicos y políticos, de manera integral, trascendiendo las fronteras disciplinarias; mediante informe técnicos multidisciplinarios e interdisciplinarios, peritajes e investigaciones no sólo vinculado a lo jurídico sino en relación con otra disciplinas, como la sociología, antropología, la historia, etc., es decir, se trata de salir de lo jurídico para interpretar pluralmente e interdisciplinariamente lo jurídico.

3) Contrastación con las vivencias y experiencias concretas de los actores, colectivos y contextos que se quiere observar (desde adentro); que según los casos, amerita la presencia de los magistrados y magistradas en la nación y pueblo indígena originario campesinos, en dialogo igualitario con sus autoridades, a objeto de intercambiar experiencias, conocerse recíprocamente, para clarificar el contexto que se pretende interpretar.

4) Oposición, y legitimación (interpretación desde abajo) que emerge de la producción oral y práctica hermenéutica de los actores sociales, bajo parámetros descolonizadores; como resultado del dialogo, que implica al mismo tiempo acuerdos, sobre el modo en que se concibe determinada institución, practica o normas de la nación y pueblo indígena originario campesino. (TCP, 2014, p. 15-16)

A sentença estabelece que estes critérios não podem ser entendidos como requisitos unívocos ou mesmo "fases" da interpretação plural, mas como lineamentos que devem ser observados quando da aplicação deste método hermenêutico (TCP, 2014, p. 16). A partir disso, a Corte passou a analisar o caso acima descrito tomando em consideração estes critérios para chegar à conclusão já anunciada. Para tanto, discutiu em um tópico especifico "a cosmovisão e a concepção filosófica da Nação Uru Chipaya com respeito à norma consultada" (TCP, 2014, p. 25) para compreender a sua forma comunitária de organização social. Da mesma forma, discute em outro tópico a "informação e análise com relação ao contexto de aplicação da norma consultada" (TCP, 2014, p. 26), no qual descreve a organização "política" daquela Nação a partir das "autoridades originarias", "autoridades tradicionais", "governo municipal” e as “organizações não-governamentais". E, por fïm, ainda descrevem, em tópico específico, as "vivências e experiências concretas para a eleição das suas autoridades municipais" (TCP, 2014, p. 27), na qual apontam para a forma em que as eleições tradicionalmente ocorrem. Com base nisso a Corte formulou sua decisão que reconhece a legitimidade jurídica e constitucional 
das autoridades da Nação Uru Chipaya, afirmando, desta forma, o principio constitucional da interculturalidade.

\section{Um "constitucionalismo intercultural"}

O reconhecimento constitucional da interculturalidade e a superação do paradigma do integracionismo e do asimilacionismo histórico impõe não somente ao Judiciário, mas também aos demais Poderes instituídos e à sociedade civil, o dever de fazê-lo cumprir, "dando vida" ao texto da Constituição que é marcado por profundas transformações para o constitucionalismo moderno. Pode-se, portanto, falar da emergência de um "constitucionalismo intercultural", categoricamente afirmado pela própria sentença analisada. Referido "constitucionalismo" nasce com o texto constitucional de 2009 , mas somente ganha vida com sua afirmação, seja pela prática política, seja pela prática judicial. Em efeito, falar de um constitucionalismo "intercultural" significa que a Constituição reconheceu a intrínseca pluralidade da sociedade, marcada por diversos grupos que coletivamente compartilham epistemologias, cosmovisões e modos de vida diferentes, e fornece um paradigma normativo para gerir a pluralidade pelo método da interculturalidade, isto é, pelo diálogo entre as diferentes culturas. Como afirma Boaventura de Sousa Santos (2005), trata-se de se utilizar de um instrumento hegemônico - o constitucionalismo moderno, nascido na França e nos Estados Unidos - para propósitos contra hegemônicos, ou seja, para a proteção de culturas que em grande medida foram marginalizadas do processo de construção da modernidade política, jurídica e constitucional.

Nesse sentido, a edificação de um "constitucionalismo intercultural" implica na criação de metodologias jurídicas para gerir o pluralismo cultural no interior do processo político boliviano - nas instituições políticas e jurídicas. O reconhecimento de uma grande diversidade de línguas (um total de 35 de acordo com o art. 5, I) e de nações (art. 3), e a garantia de "cotas" para a efetiva participação de diferentes etnias nas instituições historicamente “embranquecidas" em um país de população majoritariamente indígena (como, por exemplo, o próprio Tribunal Constitucional Plurinacional, art. 197, $\left.\mathrm{I}^{16}\right)$, da mesma forma que o aprimoramento de uma "interpretação plural" e "intercultural", conforme realizada pelo Tribunal Constitucional Plurinacional, são importantes métodos que "dão corpo" ao constitucionalismo intercultural. Pode-se ainda dizer que o constitucionalismo intercultural se

16 De acordo com a Constituição boliviana: “Artículo 197. I. El Tribunal Constitucional Plurinacional estará integrado por Magistradas y Magistrados elegidos con criterios de plurinacionalidad, con representación del sistema ordinario y del sistema indígena originario campesino." 
inscreve como um "projeto" a ser desenhado pelas instituições e pela sociedade bolivianas e, nesse sentido, ela é o "vinculo de continuidade revolucionaria" na centralidade do processo constitucional que já dura mais de 10 anos. Isso porque o reconhecimento da interculturalidade como princípio basilar do seu texto constitucional na Bolívia impõe a este último um caráter intrinsecamente dinâmico, dispondo que este deve ser conjugado e analisado com uma pluralidade de interpretações, exigindo uma abertura significativa da hermenêutica constitucional em direção ao pluralismo cultural e ao diálogo intercultural. Em efeito, isso faz com que o projeto constitucional tenha um caráter ambicioso por um lado, mas por outro, também o torna mais complexo e dificultoso.

Nesse sentido, observa-se que o reconhecimento da interculturalidade como princípio constitucional - tanto em seu texto, quanto em sua prática judicial e política - o incorpora como elemento da "identidade constitucional" (JACOBSOHN, 2010) boliviana. Como aponta Gary Jacobson, as constituições contemporâneas fazem emergir o tema da identidade no interior do processo constitucional, que emerge relacional e dialogicamente - não sendo, portanto, uma "essência". Ao reconhecer a interculturalidade como um dos "pilares" do texto constitucional e vê-lo sendo aplicado pela Corte Constitucional como princípio e método específico, a constituição boliviana posiciona a questão da identidade na centralidade da sua prática e teoria constitucional. Trata-se de uma identidade constitucional calcada na interculturalidade, isto é, na dinâmica de relações complexas entre diferentes culturas que podem, em determinados contextos, concorrer para estabelecer o sentido do referido texto constitucional.

Jacobson define a identidade em si como um processo de negociação sociopolítica, o qual pode sofrer alterações e, inclusive, mudanças - causando uma "revolução constitucional", que ocorre quando altera-se profundamente alguma disposição constitucional sem, entretanto, recorrer à violência (JACOBSOHN, 2010; JACOBSOHN \& ROZNAI, 2020). Por assim ser, ela somente mostra-se evidente quando traduz suas palavras em ações, na medida em que o texto e o contexto, a teoria e a prática constitucional, são vistas como dois lados indissociáveis de um mesmo fenômeno. O texto estabelece prescrições que somente fazem sentido se forem postas em prática pelas instâncias políticas e jurídicas, e, portanto, exigem engajamento social e político representado pelo espírito do constitucionalismo democrático. Esta negociação é marcada por desarmonias que se estabelecem no interior de sistemas políticos democráticos, mas exige compreender que "a dialogical engagement between the core commitments and its external environments is crucial to the formation and evolution of a constitutive identity" (JACONSOHN, 2010, p. 13). 
Embora Jacobson reconheça, juntamente com Amartya Sen (2006), que a questão da identidade pode ser "perigosa" para sociedades e estados, pois pode nutrir a violência como uma possível resposta no confronto político, o autor também reconhece que "the dynamics of constitutional identity are to a significant degree an expression of a developmental process endemic to the phenomenon of constitutionalism" (JACONSOHN, 2010, p. XIV) ${ }^{17}$. Nesse sentido, falar em um "constitucionalismo intercultural" significa falar na "busca" constante pelo constitucionalismo intercultural, ou seja, num processo dinâmico e complexo que busca a sua afirmação política e jurídica, pois "[...] in the end, constitutional identity will be fashioned and refashioned - through the struggle over constitutional identity"” (JACONSOHN, 2010, p. 135).

\section{Conclusão}

O reconhecimento constitucional da interculturalidade projeta-se como uma importante contribuição para o patrimônio comum do constitucionalismo democrático, abrindo o caminho para uma nova politica de gestão da diversidade no âmbito institucional. Sua afirmação pelo Tribunal Constitucional Plurinacional, mediante a criação do método interpretativo plural, reforça a compreensão de que a interculturalidade localiza-se na centralidade da teoria constitucional boliviana, de modo que todo o pensamento constitucional daquele país deve levar em consideração o dialogo intercultural e a necessidade de sincronia e compreensão mútua entre diferentes culturas, cosmovisões e práticas sociais. Trata-se da emergência tanto de uma "Constituição intercultural", quanto de um "Constitucionalismo intercultural", entendido este último como um "movimento" político-cultural e jurídico de afirmação do texto constitucional, o que aponta para a sua a construção de uma peculiar identidade constitucional intercultural boliviana.

É evidente, contudo, que o texto constitucional boliviano de 2009 foi resultado de um momento político peculiar na história boliviana que, contudo, atualmente passa por mudanças. As recentes transformações políticas na Bolívia, que desde 2018 passa por uma crise políticoinstitucional aprofundada em 2019 com a mudança de regime politico na Presidência da República, podem colocar em xeque as conquistas político-constitucionais da Carta de 2009. Entretanto, a história do constitucionalismo democrático mostra que são nos momentos de crise política que se constata a capacidade, ou não, do texto constitucional expressar sua força

\footnotetext{
${ }^{17}$ Nesse sentido, também ver: Haberle (2000).
} 
normativa. Nesse sentido, espera-se que a referida crise política não se converta também em uma "crise de direitos", ou seja, numa crise de efetividade da Constituição e da hipertrofia da sua dimensão simbólica ou mesmo da ruptura político-constitucional.

No que se refere às hipóteses deste trabalho, apresentadas na introdução, conclui-se que foram corroboradas ao longo deste percurso analítico. Cabe ressaltar, entretanto, que a experiência boliviana é atualmente um "laboratório a céu aberto" da interculturalidade e de seu manejo político-constitucional, que, de forma inovadora - juntamente com a Constituição do Equador, porém de modo mais audacioso - assume o desafio de sua afirmação e proteção constitucional, que, entretanto, não é somente o desafio do povo boliviano, mas, em maior escala e em perspectiva humanista, o desafio de toda a humanidade.

\section{Referências}

BENHABIB, Seyla. Las reivindicaciones de la cultura: igualdad y diversidad en la era global. Buenos Aires : Katz Editores, 2006.

BHABHA, Homi. Nuevas minorias, nuevos derechos: notas sobre cosmopolitismos vernáculos. Buenos Aires : Siglo XXI, 2013.

BOBBIO, Norberto. A Era dos Direitos. Rio de Janeiro : Elsevier, 2004.

BURCKHART, Thiago. Constitucionalismo e democracia: uma analise do processo eletivo de magistrados para Tribunais Superiores da Bolívia. Revista Eletrônica Direito e Politica, v. $14,2019$.

CLAVERO, Bartolomé. "Estado Plurinacional o Bolivariano: nuevo o viejo paradigma constitucional americano", 2011. Disponible en http://clavero.derechosindigenas. org/wpcontent/uploads/2011/05/EstadoPlurinacional.pdf.

FAJARDO, Raquel. Hitos del reconocimiento del pluralismo y el derecho indígena en las políticas indigenistas y el constitucionalismo andino. In: Lopez, M. B. (Org.). Pueblos indígenas y derechos humanos. Bilbau : Universidad de Deusto, 2006.

Aos 20 anos da Convenção 169 da OIT: balanço e desafios da implementação dos direitos dos Povos Indígenas na América Latina. In: VERDUM, Ricardo. Povos Indígenas: Constituições e Reformas Politicas na América Latina. Brasília : Instituto de Estudos Socioeconômicos, 2009.

FARINAS DULCE, Maria José. Democracia y Pluralismo. Madrid : Dykinson, 2014.

FERRAZZO, Debora. Pluralismo jurídico e descolonização constitucional na América Latina. Dissertação de Mestrado. Programa de Pós-graduação em Direito. Florianópolis, Universidade Federal de Santa Catarina, 2015. 
FLORES, Rocío Villanueva. La interpretación constitucional en el Estado Constitucional. Revista Derecho del Estado, n. ${ }^{\circ}$ 34, enero-junio de 2015.

GARGARELLA, Roberto. Latin american constitutionalism, 1810-2010: the engine room of the Constitution. Oxford: Oxford University Press, 2013.

HÄBERLE, Peter. Teoria de la Constitución como ciencia de la cultura. Tradução de Emilio Mikunda. Madrid: Tecnos, 2000.

HABERMAS, Juergen. Direito e democracia : entre facticidade e validade. 2a. Ediçao. Rio de Janeiro : Tempo brasileiro, 1997.

HALL, STuart. A identidade cultural na pós-modernidade. Rio de Janeiro : DP\&A, 2010.

HELD, David. Modelos de democracia. Madrid : Alianza Universidad, 1991.

JACOBSOHN, Gary Jeffrey. Constitutional Identity. Harvard University Press : Cambridge, 2010.

JACOBSOHN, Gary Jeffrey \& ROZNAI, Yaniv. Constitutional Revolution. Yale University Press : New Haven, 2020.

LOPES, Ana Maria D'Avila. Da coexistência à convivência com o outro: entre o multiculturalismo e a interculturalidade. Revista Interdisciplinar de Mobilidade Urbana, vol. 20, n. 38, pp. 67-81, 2012.

MACHICADO, Jorge. Derecho Constitucional Boliviano. Sucre : Universidad San Francisco Xavier, 2009.

PANNAIN, Rafaela. A reconfiguração da política boliviana: reconstituição de um ciclo de crises. Lua Nova, n. 105, São Paulo, set/dez 2018.

PIOVESAN, Flavia. Direitos humanos e o direito constitucional internacional. São Paulo : Saraiva, 2005.

QUIJANO, Aníbal. Colonialidade do poder e classificação social. In: SANTOS, Boaventura de Sousa. MENESES, Maria Paula. Epistemologias do Sul. São Paulo: 2010. pp. 84-130.

RAMOS, Alcida Rita. Constituições nacionais e povos indígenas. Belo Horizonte : Editora da UFMG, 2012.

Indigenism: ethnic politics in Brazil. Madinson, Wisconsin : The University of Wisconsin Press, 1997.

SANTOS, Boaventura de Sousa \& RODRIGUEZ, José Luis Exeni (Org.). Justicia indigena, plurinacionalidad e interculturalidad en Bolivia. La Paz : Abya-Yala, Fundacion Rosa Luxemburgo, 2012. 
SANTOS, Boaventura \& MENESES, Maria Paula (Org.). Epistemologias do Sul. Coimbra, Almedina, 2009.

SANTOS, Boaventura. Refundacion del Estado en América Latina: perspectivas desde una epistemologia del Sur. Lima : Red Latinoamericana de Antropologia Juridica (RELAJU), 2010 . 1997.

Pelas mãos de Alice: o social e o político na pós-modernidade. São Paulo : Cortez,

El uso contra-hegemónico del derecho en la lucha por una globalización desde abajo.

Anales de la Cátedra Francisco Suárez, n. 39, 363-420, 2005.

SEMPRINI, Andrea. Multiculturalismo. EDUSC : Bauru, 1999.

SEN, Amartya. Identity and violence: the illusion of destiny. London : Penguin Books, 2006.

TOURAINE, Alain. Um novo paradigma. Para compreender o mundo de hoje. Traduçao de Gentil Avelino Titton. Petropolis : Vozes, 2007.

TRIBUNAL CONSTITUCIONAL PLURINACIONAL. Declaracion Constitucional Plurinacional 0030/2014. Consulta de Autoridades Indigena Originario Campesino. Sala Primera Especializada, Relator: Tata Gualberto Cusi Mamani, Sucre, 28 mayo 2014.

TUBINO, Fidel. "Entre el multiculturalismo y la interculturalidad: más allá de la discriminación positiva”, Derecho \& Sociedad, (19), 299-311, 2002.

La interculturalidad crítica como proyecto ético político. Ponencia presentada en el Encuentro Continental de Educadores Agustinos, Lima, 24-28 de enero de 2005.

VILLAS BÔAS FILHO, Orlando. A juridicização e o campo indigenista no Brasil: uma abordagem interdisciplinar, Revista da Faculdade de Direito da USP, v. 111, 2017.

Os direitos indígenas no Brasil contemporâneo. In: BITTAR, Eduardo (Org.). História do Direito Brasileiro: leituras da ordem jurídica nacional. São Paulo : Atlas, 2003.

WALSH, Catherine. Interculturalidad, plurinacionalidad y decolonialidad: las urgencias político-epistémicas de refundar el Estado, Revista Tabula Rasa, Bogotá, n. 9, jul-dec. 2008.

Interculturalidad critica y educacion intercultural. In: VIAÑA, J; TAPIA, L.;

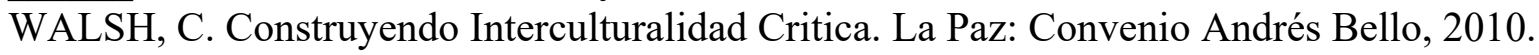

